SPECIAL ISSUE: ARTICLE

Lab and Field Experiments

\title{
Distance to news: how social media information affects bribe-giving in India
}

\author{
Jun Goto ${ }^{1} \cdot$ Takashi Kurosaki $^{2} \cdot$ Yuko Mori $^{3}$
}

Received: 14 May 2021 / Revised: 28 June 2021 / Accepted: 12 July 2021 /

Published online: 11 October 2021

(C) The Author(s) 2021

\begin{abstract}
While recent empirical evidence reveals some effective interventions in preventing corruption among bureaucrats and politicians, there has been little discussion on how to prevent the bribe-giving behavior of ordinary citizens. This paper investigates the role of social media information in influencing the supply of bribes by citizens instead of the demand side. We, therefore, developed and published an original news application in India and implemented a 3-month experiment. In this application, we randomly circulate live news related to corruption to users and incorporate a lab experiment into the app system to elicit users' bribery behavior every week. We find that corruption news involving politicians within a close geographical proximity lowers users' moral costs against the anti-social bribery act, leading to an increase in the amount of bribes. However, news of accused citizens and officials within the geographic proximity increases their moral cost against bribes and decreases the amount. This suggests that individually tailored local information on corruption may be an effective tool to reduce citizens' supply of bribes.
\end{abstract}

Keywords Local news $\cdot$ Bribe $\cdot$ Social media $\cdot$ Mobile application

Jun Goto

gotojun.jg@gmail.com

Takashi Kurosaki

kurosaki@ier.hit-u.ac.jp

Yuko Mori

y_mori@tsuda.ac.jp

1 Kobe University, Kobe, Japan

2 Hitotsubashi University, Tokyo, Japan

3 Tsuda University, Tokyo, Japan 


\section{Introduction}

Corruption is prevalent and persists in society. A number of studies show that corruption is considered as one of the main obstacles to achieving efficient economic activities in developing countries (Knack and Keefer, 1995; Mauro, 1995; Bertrand et al., 2007). In contemplating how to mitigate perpetuating corruption, it is important to recognize that such transactions involve both bribe-takers and bribe-payers. In particular, under inefficient institutions and malfunctioning bureaucracy, some citizens may be willing to pay a collusive bribe that aims to obtain extra benefits from a public official. For instance, citizens may want to pay extra fees to expedite the delivery of public services. ${ }^{1}$ Therefore, it is essential to understand the factors shaping the bribe-takers and bribe-payers behavior to devise effective policies. However, most previous studies that have examined effective means of eradicating corruption have focused on the demand side of a bribe, that is, the bureaucratic side for requiring bribery. Very few have focused on the supply side, that is, the citizen side for giving bribery. Consequently, little is known about why some citizens voluntarily opt to pay bribes and how such bribery behavior can be prevented.

A sense of morality on anti-social behavior may perform an important role in the widespread bribe-giving. Namely, when people observe others engaging in antisocial behavior, their moral cost of such behavior decreases and people are more likely to engage in the same behavior (Abbink et al., 2018; Dimant, 2019; Bicchieri et al., 2020). ${ }^{2}$ In this situation, raising the moral cost associated with bribe-giving becomes key in eliminating corruption from society. As an effective intervention to alter such moral costs, information-based interventions are gaining attention in economics (Bursztyn and Jensen, 2017; Bursztyn et al., 2019). However, evidence regarding the impact of information-based interventions on bribe-giving behavior is still scarce.

This paper examines the impact of information related to corruption on citizens' bribe-giving behavior. It focuses on daily news circulated through social media: How does exposure to information about others' involvement in corruption influence citizens' bribe-giving behavior? To provide empirical evidence for this research question, it is necessary to explicitly consider how geographically distant locations news information refers to and who is involved in it. Namely, how do people's moral costs of giving a bribe change when they are informed that others geographically close to them are engaged in corruption? Would the impact on the moral costs change if the information about engaging in corruption is about politicians rather than about ordinary citizens?

\footnotetext{
1 United Nations Convention Against Corruption provides technical guidance on the means to tackle corruption and emphasizes the importance of breaking collusion between bribe payers and takers. See https://www.unodc.org/documents/corruption/Technical_Guide_UNCAC.pdf. India, one of the countries that ratify this convention, has recently passed the Prevention of Corruption (Amendment) Act 2018 to expand offences for persons who give a bribe.

2 Following Gazzaniga (2005) and Levitt and List (2007), we define a moral cost as the psychological burden that people perceive when they act in a way that violates their moral values and/or social norms.
} 
Considering the distance from news and the identity of actors involved in it is critically important, because it enables us to identify the factors shaping the moral costs for giving a bribe. On the one hand, we expect that when people obtain information that others geographically close to them are being punished for bribe-giving, their moral costs will increase, because they will be reminded that bribe-giving is an illegal act and against social rules. On the other hand, information that a person distant from them has been punished for bribe-giving may not affect people's moral costs as much. Therefore, the effect of the daily news on the moral costs depends on the geographic proximity to the case referenced in that news. This relationship could be different in the case of politicians' corruption: if the politicians elected from their own constituencies are corrupt, people's moral costs will decrease and people may think that it is acceptable for them to also pay bribes. Consequently, it is expected that moral costs will be lowered by local corruption news about the politicians who represent their community.

In investigating the impact of the information, we focus on the role of daily news, because such information is deemed as the most common type of information that ordinary people are exposed to on a daily basis. Thus, it has relatively high external validity. However, revealing the causal impact of the daily news on bribe-giving is prohibitively difficult for the following reasons: (i) it is technically challenging to accurately grasp the information on what news people are exposed to in the current society, where a news flow is individually tailored by social media instead of mass media; (ii) which news people choose to consume is endogenous and depends on their observable and unobservable attributes; and (iii) it is also a difficult task to obtain information on bribe-giving or to measure people's preferences toward bribery in a way that is linked to news consumption information inside social media.

We developed an original mobile application to overcome these problems and implemented a 3-month experiment for registered users. Our mobile application called BribeWatch is a simple news curation app involving the following two experiments: a field and a lab-in-the-app experiment. First, the field experiment is built into the app to randomly circulate daily news. More specifically, the app is designed to crawl more than 75,000 news and blog websites to construct an original database of news and blog articles containing corruption-related keywords. ${ }^{3}$ This database is scheduled to be updated every $3 \mathrm{~h}$. Then, the app delivers 40 randomly selected articles from its database to each user every time it is updated. This field experiment, which randomly distributes articles, can create exogenous variations for each user in terms of distance to news that they are exposed to.

Second, we incorporated a lab experiment into the app. For this purpose, we implemented a modified version of the bribery experiment every week during the

\footnotetext{
3 We rely on NewsAPI to develop our app. NewsAPI returns the JSON search results that contain information regarding articles and breaking news headlines from target news sources and blogs across the web. See their website (https://newsapi.org/) for a more detailed explanation about this API. Note that we added some additional web sources that were not originally included in this API. We used the following keywords to collect articles: corruption, bribe, bribery, and graft.
} 
entire experimental period. ${ }^{4}$ In this lab-in-the-app experiment, the algorithm randomly forms an anonymous group consisting of three users. Each of the three users is assigned to one of three roles: a citizen, a public official, or a third person. As the first mover, the citizen requests the public official to issue them a licence and simultaneously decides whether they will pay a bribe to the public official to increase the probability of obtaining the licence. If the official accepts the bribe, the third person's endowment is reduced even though they have nothing to do with the bribe. However, the third person can, at a fixed cost from their endowment, punish a citizen belonging to a different group who is not directly matched to them. Put differently, the third person is allowed to indirectly punish a citizen assigned to a different group, forgoing some of their own endowment. This weekly experiment can elicit the dynamics of user's propensity to commit, accept, and punish bribery behavior. Among them, we exploit the information of bribe-giving as the citizen in this experiment to construct an outcome variable in the empirical analysis.

Our identification strategy builds on the within-subject variations regarding the distance to locations that news articles refer to. Intuitively, we compare the results of the lab experiment for the week in which users receive news about corruption cases that are geographically close to their residential locations to the results of the week in which they receive news about cases that are far away from them. We separately estimate the impact of the distance to news on the giving of bribery in accordance with the identity of actors involved in news. First, we focus on the local news stories that address cases, where ordinary citizens and public officials have been arrested for corruption. Second, we target news stories that cover cases, where politicians have been accused of corruption.

It is worth noting that our experimental design has the advantage of identifying the impact of the distance to the news on the moral costs of bribery behavior: the propensity to give a bribe, measured by the lab experiment, is not directly affected by the probability of being arrested in the real world. Therefore, even if exposure to news about the arrest of other citizens alters not only the moral costs of bribe-giving but also the user's subjective probability of being arrested in the real world, our empirical strategy can still exclusively extract the effect of the news on the moral costs.

We officially published this mobile app in the Google Play Store, one of the largest app stores in the world. During the experimental period, only those who lived in India and were older than 18 years could download the app. The first user was registered on May 19, 2020. The total number of users reached 1053 by June 25, 2020. The app service was terminated on August 11, 2020. As a result, the person who registered for the longest period used the app for 84 days and even the person who registered for the shortest period used it for 47 days. The high participation rate of users is due to the fact that we gave users monetary incentives proportional to their in-app behavior. Users earned the app's own currency for each log into the system,

\footnotetext{
4 The bribery experiment has been widely conducted in various countries and cultures (Abbink et al., 2018; Alatas et al., 2009; Banuri and Eckel , 2012a; Barr and Serra, 2010; Cameron et al., 2009). We have modified the bribery experiment conducted by Barr and Serra (2010) as it fits our context the most among them. See Sect. 2.2 for a more detailed explanation on our lab experimental design.
} 
each news item they viewed, each comment they posted, and each experimental session they participated in. The app's original currency can be converted to online gift cards such as the Amazon Gift Card. This incentive scheme ensured users' active information consumption.

Our empirical analysis obtains three main findings. First, the exposure to news reports that ordinary citizens involved in corruption have been arrested in India reduces the amount of bribe-giving in the lab experiment by $2.3 \%$ on average if the distance from the location covered by the news becomes shorter by one standard deviation. ${ }^{5}$ Consistent with this result, the amount of bribe-giving decreases when the referenced location of the news about the public's involvement in corruption coincides with users' residential areas. Second, when the content of the news is replaced with the involvement of politicians instead of ordinary citizens, the result becomes reversed: the amount of bribe-giving increases by $2.4 \%$ on average if the distance to the news of politicians' corruption becomes shorter by one standard deviation. Finally, we explore mechanisms behind the impacts of the distance to the news. Using additional information from the lab-in-the-app experiment, we identify the following mechanisms. In politicians' cases, the exposure to the news within the geographic proximity decreases the moral costs against bribe-giving, because users may recognize it as the less anti-social act by learning that even the person who should be their role model commits bribes. This decrease in moral costs results in an increase in the amount of bribe-giving. In citizens' cases, the exposure to the local news increases the moral costs, because users are reminded that bribe-giving is actually illegal and against social rules, leading to the decrease in the amount of bribe-giving.

We contribute to three strands of the literature. First, and most significantly, our paper makes a major contribution to the literature on corruption using field experiments in developing countries (Olken and Pande, 2012). Previous works mainly focus on the impact of (a) increased transparency of bureaucrats and government by disclosing particular information in public on (b) the bribe-taker's behavior or the demand side of bribes, relying on (c) the relatively short-term experiments. This paper adds the first empirical evidence on a combination of (a) daily information that is publicly available for the entire population through social media rather than intervention-specific information, such as auditing of government activities, (b) the supply side of bribery behavior rather than the demand side from bureaucrats, and (c) the relatively long-term intervention with time-variant outcome information on bribe-giving elicited by repeated lab experiments.

Our paper also contributes to the literature on the bribery experiment (Abbink, 2006; Banuri and Eckel, 2012b). Among them, our paper is closely related to Abbink et al. (2018) who investigate the impact of descriptive social norms on bribe offers by a firm to a public official. We add another evidence regarding cultural determinants of bribe-offering by focusing on the influence of daily information on moral costs using a combination of field and lab experiments. Finally, we contribute to the emerging literature on the role of social media in modern society. Evidence has been accumulated on how political polarization arises across countries through the

\footnotetext{
${ }^{5}$ In our data, one standard deviation is approximately equal to $600 \mathrm{~km}$.
} 
penetration of social media (Boxell et al., 2017; Levy, 2021; Prior, 2013). However, little is known about whether social media information affects anti-social behavior rather than political preferences. Our paper is unique, since it relates social media information to a typical anti-social behavior in developing countries, that is, bribery behavior. We present new evidence that people change their anti-social behavior in response to the social media information depending on their proximity to the news.

\section{Experimental design}

This section provides a detailed explanation on the design of our experiment which was implemented through a newly developed mobile application. First, we elaborate on the information circulation system and the built-in randomizations in the app. Second, we describe the structures and procedures of the lab-in-the-app experiment: a modified version of the bribery experiment implemented by Barr and Serra (2010). We choose this experimental design, because it fits our context the best out of the similar experiments (Abbink et al., 2018; Alatas et al., 2009; Banuri and Eckel, 2012a; Barr and Serra, 2010; Cameron et al., 2009). Finally, we explain how we incentivize individuals to actively use our app by institutionalizing the exchange system between in-app currency and e-commerce gift cards, such as the Amazon Gift Card.

\subsection{An original mobile application}

We developed the original mobile application called BribeWatch. BribeWatch is a simple news application: the information curation system is built into this app in which our original web crawler extensively collects all entries related to corruption topics from over 75,000 websites. Then, it immediately distributes the collected entries to users. Target websites range from official news sites, e.g., BBC to more informal ones including personal blog posts. This system aims to help users find relevant content on corruption without having to spend time on search engines and/or other social media to browse multiple news sources by themselves. ${ }^{6}$

Create an original database. We will now elaborate on how we collect and circulate news and blog articles to individual users. At the beginning, we need to create an original database. For this task, we built algorithms to crawl all the news sites listed in the Python library called News API and all blog entries on major blogging platforms to pick up articles which were written within the last 30 days and contained any of the following words: bribe, bribery, corruption, or graft. ${ }^{7}$ Then, we construct the corruption-related-articles database based on the search results. Note that selected articles are internally categorized into two groups in our database:

\footnotetext{
${ }^{6}$ In addition to the news curation system, the app provides an online platform for users to exchange their opinions particularly regarding each entry that we distribute. In this study, we only use the information collected from the news curation system.

7 As major blogging platforms, we focus on Blogger.com, WordPress.com, Tumblr.com, Medium.com, and Linkedin.com.
} 
if articles refer to corruption cases in India they are assigned to Group 1; they are assigned to Group 2 otherwise. We updated our database every $3 \mathrm{~h}$.

Randomized information circulation. Every 3 h, we randomly selected 20 articles for each user from Groups 1 and 2, respectively. Thus, we delivered 320 articles in total to individual users every day. Note that the number of articles which are displayed at each user interface is always fixed at 40 and we do not allow users to access archived article data. Therefore, they are not able to access past news and blog posts that were delivered more than $3 \mathrm{~h}$ ago. ${ }^{8}$ This design enables us to avoid situations, where some users may always read the same articles when a lineup of articles is individually accumulated over time. Using this design, we can create variations in the information that users consume over time. These time-variant variations within users are necessary for the identification strategies mentioned below.

Randomized timing of pop-up notifications. In our app, after a certain amount of time has passed, since the user logged in, a pop-up appears on the screen and is designed to prompt the user to take a certain action. After this pop-up appears, each user cannot continue reading the news unless they complete the action specified there. There are two types of pop-ups: the first one asks users to enter a comment on an article; and the second one asks them to play a lab experiment. The timing of the pop-ups is fully randomized, and the user cannot predict when the pop-up will restrict their actions. Importantly, each user is only permitted to enter comments and participate in the experiment when a pop-up appears. Taken together, this pop-up system exogenously determines when users write comments and when they play lab experiments. ${ }^{9}$

Incentives for active usages. We created an in-app currency called BribeWatchPoint (BWP), which is linked to in-app actions. Each user can receive up to 480 points per week. The BWP can be exchanged for a 200 rupee Amazon Gift Card when 200 points are accumulated in total. Points are lost when they are exchanged for Amazon Gift Cards. A user can earn BWPs by completing the following tasks. First, 100 BWPs are endowed when users complete their registration and a baseline survey. Second, users can earn one BWP every time they log in each day. However, it is limited to a maximum of five points per day. Third, users can earn 0.1 BWPs every time they click on a delivered article to check its content. Forty articles are delivered to each user every $3 \mathrm{~h}$, so if a user reads all the articles in $24 \mathrm{~h}$, they can earn 32 BWPs at maximum. Third, each time a user enters a comment on a distributed article, they can earn one BWP. However, the comment must be between 80

\footnotetext{
8 Technically speaking, users can be exposed to the same articles even after the every-3-h update if those articles remain in the database after this update and are randomly selected to be circulated to the same individuals again.

${ }^{9}$ In addition to these randomizations, we also implement a randomized display of comments. To be more precise, we encourage all users to express their own opinions for each article and facilitate online discussions among them. For this purpose, we prepared a comment box under each article and asked each user to express their opinions on the article. We accumulated all comments and created the comment-by-user database. Then, we deployed three comments, which were actually posted by other users, below each article's title. We randomly selected these three comments from our database and updated them every $3 \mathrm{~h}$ similar to the main articles. Note that some articles are supposed to be distributed to users without any comments as no users post opinions for those articles yet.
} 
and 300 words in length. In addition, each user can only earn BWP for one comment per news article. Multiple comments will not be eligible for points. Fourth, each user can participate once a week in the lab experiment, where they can earn BWP based on their actions in the game.

\subsection{A lab-in-the-app experiment}

We modified the standard bribery experiment and incorporated it into the app to measure each user's propensity to commit, accept, and punish bribery behavior. Here, we explain the detailed design of the experiment and implementation processes.

\subsubsection{The bribery experiment with a punishment opportunity}

At the beginning, the algorithm randomly forms experimental groups, each of which consists of three users. Each user is randomly assigned to one of the following roles: a citizen, a public official, or a third person. All experimental sessions were implemented in an anonymous setting, and users could not identify with whom they were matched. Experimental groups were randomly shuffled every session. Each user was allowed to play one experimental session per week.

Citizen's move. The experimenter gives an initial endowment equivalent to 35 BWPs to the citizen. As a first mover, the citizen is asked to decide whether or not to send bribes to the public official, and if so, how much to send. A bribe is supposed to increase the probability that the public official provides a qualified service in exchange for accepting it. We define that the value of this service is equal to 16 BWPs. If the citizen makes a bribe $(b)$, one BWP will be deducted from the initially endowed points, regardless of its amount and whether the official accepts it or not. This arrangement is intended to replicate the real situation, where there is a certain probability that a bribe will be found and then the bribe-giver will be accused of corrupt behavior. Consequently, the citizen will get paid 35 BWPs if they do not commit a bribe and get no service from the public official. They will receive 51 BWPs if they do not commit a bribe but get a qualified service. Alternatively, they will get 50 BWPs minus $b$ if they commit a bribe and get a qualified service.

Public official's move. The public official is endowed with 35 BWPs. They have to decide whether to accept a bribe offered by the citizen. If a bribe is accepted, the official must immediately provide a service to the citizen. This provision of the service involves a cost equivalent to five BWPs. This cost accrues from not only the direct cost of the service provision itself but also from the possibility of being penalized if the fact that they accept a bribe is disclosed to the public. Thus, the final payoff for the public official is 35 BWPs if they are not offered a bribe or reject it. Alternatively, it is equal to $30 \mathrm{BWPs}$ plus $b$ otherwise.

Third person's move. The third person is endowed with 25 BWPs. Their endowment is reduced by four BWPs if the citizen sends a bribe, and the public official accepts it. This reflects the fact that bribes can be beneficial to individual citizens 
but harmful to society as a whole. ${ }^{10}$ Here, we give an opportunity of punishment to the third person. If they can bear a cost equivalent to one BWP, they can punish the citizen who commits a bribe and reduce the citizen's endowment by 1 BWP. ${ }^{11}$ Note that we allow the third person to impose a sanction on the citizen who belongs to a different group from them. In other words, the direct retaliation by the third person toward the citizen who belongs to the same group is not permitted in this setting. ${ }^{12}$

\subsubsection{Implementation and reward calculation}

We built this experiment into the app. As mentioned above, each user is allowed to play the experiment once a week. The timing of joining an experimental session is exogenously determined by the app. More concretely, the BWP payments are made on a fixed day each week. In addition, a random pop-up is set to appear for each user at a randomly-selected point in the week between the last and the next payment dates. Therefore, when the payment date arrives, the number of times that users can play the experiment is reset to one. Once the user plays the experiment, that number turns to be zero and will not be reset to one until the next payment date occurs. This means that it is practically impossible for all subjects to participate in the experiment at the same time. Therefore, we adopt the strategy elicitation method in which each user is required to play all roles and to elicit their possible strategies. Each user should answer the amount of bribes they want to offer as the citizen, the minimum amount of bribes that they require to provide the service as the public official, and the maximum allowable amount of bribes above which they impose punishment on the citizen belonging to a different group. All the information elicited by this method is stored in our database and updated every week according to the actual decisions made by the users. Using this database, we implemented the experimental sessions on the payment day of each week and calculated each user's reward. We make it clear to users how matching will be done and how we calculate rewards each time before they play the experiment.

The following example illustrates the calculation of rewards in our lab experiment. Suppose that, using a strategy method, the citizen decides to send a bribe of 5 BWPs to the official. The official declares that their minimum required bribe level to provide a public service is 3 BWPs. Simultaneously, the third person declares that the maximum allowable bribe level is 2 BWPs. In this case, the citizen's bribe offer will be accepted by the official, and the service will be provided. In addition, since the level of the bribe exceeds the third party's acceptable level, a penalty is triggered. As a result, the citizen's reward is 35 (endowment) -5 (bribe) -1

\footnotetext{
${ }_{10}$ If the official does not accept the bribe, we do not reduce the third person's endowment.

11 Technically speaking, we asked the third person to answer the maximum allowable bribe amount in each session. If the actual amount of bribes sent by the matched citizen exceeds it, the punishment is triggered. Therefore, cost reduction by punishment is enforced, regardless of whether the official took the bribe. Moreover, by design, the third person can overlook the citizen who commits a bribe if their maximum allowable bribe amount is equal to 35 BWPs. The detailed explanation of this strategy elicitation method and reward calculation will be provided in Sect. 2.2.2.

12 To keep the experimental design as simple as possible, we do not provide an option for the third person to punish the public official, although it would be an interesting treatment.
} 
(bribe cost) -1 (punishment) +16 (service $)=44$ BWPs; the official's reward is 35 (endowment) -5 (service cost $)+5$ (bribe) $=35$ BWPs; the third person's reward is 25 (endowment) -4 (bribe externality cost $)-1$ (punishment cost) $=20$ BWPs.

Now, suppose that all decisions remain the same except for the official's one: the official's minimum required bribe level to provide a public service is now 6 BWPs rather than 3 BWPs. In this case, the bribe offer is not accepted by the official, and the citizen cannot receive the service. Note that, even in this case, the punishment is enforced, since the bribe still exceeds the allowable amount of the third person. As a result, the following rewards are realized. The citizen's reward is 35 (endowment) -1 (punishment) $=34$ BWPs; the official's reward is 35 (endowment); the third person's reward is 25 (endowment) -1 (punishment cost) $=24$ BWPs.

Each user needs to go through the tutorial session before playing the first experiment to properly understand the entire structure of the experiment and reward calculation. This tutorial session can be accessed at any time from the app and can also be viewed outside the timing of playing the experiment. After the tutorial session, there is a quiz to check if each user understands the experiment correctly. If not, they are not allowed to proceed to the main experimental session. It is worth noting that we actually use the term "bribe", "citizen", and "public official" in all experimental sessions, and therefore, all users understand that the experiment is related to bribery actions.

\section{Data}

In this section, we explain how to construct the key variables for our econometric analysis: an outcome variable regarding the propensity to commit bribe-giving and treatment variables regarding the distance to a location referenced by news involving ordinary citizens and politicians, respectively.

\subsection{Basic information}

Our sample. We officially published the mobile app in the Google Play Store, one of the largest app stores in the world. ${ }^{13}$ Only those who live in India and are aged above 18 years can download it during the experimental period. Figure 1 shows the total number of users who registered for our app. The first user registered on May 19, 2020. The number of users had rapidly increased over time and it reached 109 two weeks after its release. The number continued to increase steadily, reaching 1000 users within a month of its release. When we reached 1053 users on June 25, 2020, we suspended recruitment of new users due to budget constraints. The service of the

\footnotetext{
${ }^{13}$ We decided to publish our app only on the Google Play Store for Android but not on the App Store for iOS, because Android has a huge market share in India, and creating an app for iOS would require a different development tool than Android, which would require additional time and budgets before we could launch the project. According to Statista Research Department, Android had a 95.23\% share of the Indian mobile OS market in 2020. This was followed by Apple's iOS, which had a 3.2\% share. See https://www. statista.com/statistics/262157/market-share-held-by-mobile-operating-systems-in-india/ for more detailed information.
} 


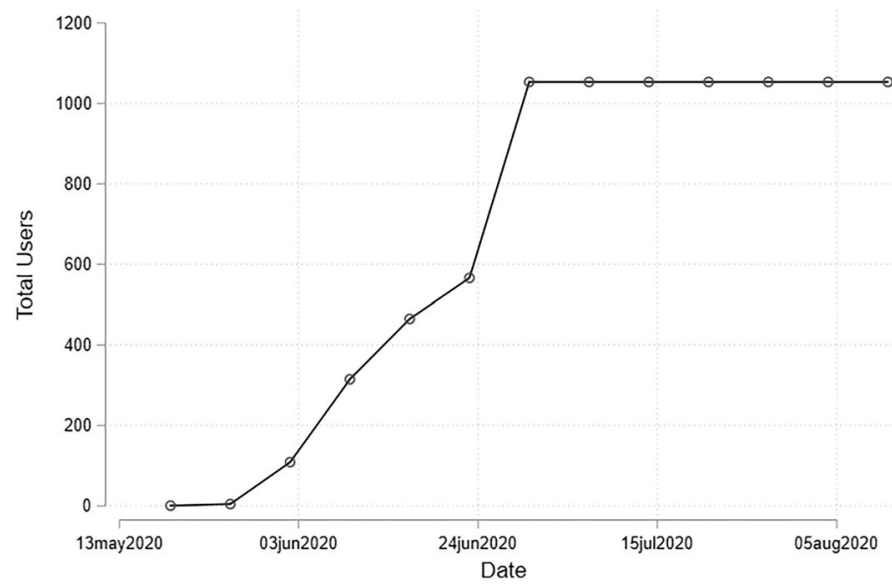

Fig. 1 Total number of users. This figure documents the total number of users who registered on our app during the experimental period. When we reached 1053 users, we stopped recruiting users due to operational constraints. In our app, it is strictly forbidden for a user to create more than one account, and we deactivated the user's account when we found it

app was terminated completely on August 11,2020. As a result, the person who registered for the longest period used the app for 84 days and even the person with the shortest period used it for 47 days.

Baseline information. When a user downloads our app for the first time, the basic questionnaire survey and the first lab-in-the-app experiment are programmed to begin immediately. According to Panel A of Table 1 which shows the summary statistics of the baseline survey, the average age of the users is 33.64 years with a standard deviation of 10.99: a wide range of users from 18- to 72-year-old participate in our app. Of these, $67 \%$ are male, $14.3 \%$ are students, $28.4 \%$ are single, and $9.78 \%$ belong to either scheduled castes or tribes. When we look at occupation structures, only $2.75 \%$ of the users are public officials who may be in a position to request a bribe, indicating that almost all the users are ordinary citizens and are likely to be in the potential position of bribe-givers. Among all users, $91.9 \%$ have an experience being asked for a bribe, which is consistent with the fact that corruption is deeply rooted in the Indian society. We encouraged each user to invite those who are connected with them in Twitter and/or other social networking sites to join our app: if a user introduces a new user to whom they are connected through online communities, they will get paid rewards. This design creates variations in terms of a scale of social networks for each user. The average number of socially connected users within the app is equal to 12.03 , while $14.8 \%$ are totally isolated, since they have no connections with other users. In the empirical analysis, we utilize this information to identify how a scale of social networks amplifies the impact of the distance to the news locations on bribe-giving. 
Table 1 Summary statistics

\begin{tabular}{|c|c|c|c|c|c|}
\hline & Obs. & Mean & S.D. & Min & Max \\
\hline \multicolumn{6}{|l|}{ Panel A: User's characteristics in the baseline survey } \\
\hline Age & 1053 & 33.64 & 10.99 & 18 & 72 \\
\hline Student & 1053 & 0.143 & 0.351 & 0 & 1 \\
\hline Male & 1053 & 0.670 & 0.470 & 0 & 1 \\
\hline Single & 1053 & 0.284 & 0.451 & 0 & 1 \\
\hline Schedueled castes/tribes & 1053 & 0.0978 & 0.297 & 0 & 1 \\
\hline Public official & 1053 & 0.0275 & 0.164 & 0 & 1 \\
\hline Have you ever been asked for a bribe before? & 1053 & 0.919 & 0.273 & 0 & 1 \\
\hline $\begin{array}{l}\text { Network scale (no. of socially connceted users within the } \\
\text { app) }\end{array}$ & 1053 & 12.03 & 8.939 & 0 & 44 \\
\hline \multicolumn{6}{|l|}{ Panel B: Decisions in the lab-in-the-app experiment } \\
\hline An offer amount of bribes as the citizen & 7682 & 11.19 & 7.890 & 0 & 35 \\
\hline $\begin{array}{l}\text { A min requirement of bribes to provide a service as the } \\
\text { official }\end{array}$ & 7682 & 5.727 & 3.941 & 0 & 22 \\
\hline A max allowabel amount of bribes as the third person & 7682 & 12.40 & 7.198 & 0 & 35 \\
\hline \multicolumn{6}{|l|}{ Panel C: Distance to location referenced in news articles } \\
\hline Politician's case in India (km) & 2230169 & 946.66 & 647.29 & 0 & 2335 \\
\hline Citizen's case in India (km) & 3759429 & 898.06 & 588.98 & 0 & 2081 \\
\hline Politician's case outside India (100 km) & 3779276 & 51.08 & 28.95 & 0.211 & 117.42 \\
\hline Citizen's case outside India (100 km) & 1240956 & 59.33 & 26.18 & 0.108 & 119.55 \\
\hline
\end{tabular}

Panel A of this table shows the summary statistics of users' characteristics in a baseline survey. "Student" is a dummy variable taking the value of one if a user is a student; "Scheduled castes/tribes" denotes a dummy variable taking the value of one if a user belongs to either scheduled castes or tribes; "Public official" denotes a dummy variable taking the value of one if a user's occupation is a public official or a public servant. Panel B of this table shows the summary statistics of decisions in the lab-in-theapp experiment. Panel $\mathrm{C}$ shows the summary statistics of the distance to the location referenced in news articles inside and outside India. We separately show this distance for politician's and citizen's cases. Note that the number of observations denotes the total number of news that were actually distributed to users during the experimental period and thus, this number would count the same news articles with multiple times if they are distributed to multiple users at the same time. It would also be applied if they are distributed multiple times even within users over time

\subsection{Construction of key variables}

\subsubsection{An outcome variable}

To examine the impacts of social media news on bribe-giving, we need to quantify each user's propensity to commit a bribe. To do so, we utilize the result of the lab-in-the-app experiment. As mentioned in Sect. 2.2, we implemented the bribery experiment with a punishment opportunity. Since we adopted the strategy elicitation method in each experimental session every week, we have information on decisions made by a user as the citizen, the official, and the third person in each session. Panel B of Table 1 documents the summary statistics of the lab-in-the-app experiment. On average, the citizen offers 11.19 BWPs as a bribe to the official; the official requires 
5.73 BWPs to provide a service; the third person imposes a punishment if an amount of bribes exceeds 12.4 BWPs.

It is worth noting that the amount of bribe-giving has considerable variations, both between and within subjects. First, there are $7.81 \%$ of users who send nothing as a bribe at least once throughout all the experimental sessions, while $4.88 \%$ send the maximum amount of bribes (35 BWPs). Although the giving of bribery is punishable with imprisonment up to 7 years or a fine in India, many citizens are willing to pay a bribe to request public services. This is consistent with the reality in India, and thus, our lab-in-the-app experiment seems to successfully replicate the situation. Second, when we look at the difference between the maximum and minimum values of bribe-giving within a subject, it is 18.31 BWPs on average, which implies subject's decision on bribe-giving prominently varies over time and many subjects elicit large time-series swings in bribe amounts. These facts suggest that it is much worth examining what can explain these variations and whether social media news has any influence in determining the giving of bribery.

\subsubsection{Construction of treatment variables}

In the main empirical analysis, we define a treatment variable as the average geographical distance between a location referenced by a news report and a user's residential area in each week. We construct this distance variable for news involving citizens and politicians, respectively. This section provides an explanation of how to construct these key treatment variables.

Extraction of location-specific news articles. First, we need to classify all news received by the users into those that mention specific geographic locations and those that do not. We will perform this classification separately for news within and outside India. The term "specific geographic location" here corresponds to cities, towns, and villages as defined in the Census of India for the domestic case. ${ }^{14}$ For the case outside India, it corresponds to the cities and towns listed in the World Cities Database. ${ }^{15}$ As a result of the classification, $58.2 \%$ of the total number of articles that were actually distributed to the users were categorized as location-specific news articles. If the multiple location information was included in a given news article, the location was uniquely defined by the following condition: it must have the highest frequency of occurrence in an article; if the frequency of the occurrence was equal among the candidates, the location that appeared first in an article was selected. Figure 2 shows the top 20 locations mentioned in the news, sorted by frequency.

\footnotetext{
14 According to the Census of India, a village is the basic unit for rural areas corresponding to the revenue village, which has definite surveyed boundaries. Each habitation area with locally recognized boundaries is treated as one village. A town is categorized into statutory towns and census towns: the former refers to all places with a municipality, corporation, cantonment board or notified town area committee, while the latter refers to all other places satisfying that (i) a population is equal to or exceeds 5000, (ii) at least $75 \%$ of the male working population is engaged in non-agricultural pursuits, and (iii) a population density is equal to or exceeds 400 per $\mathrm{km} 2$.

15 We use a complete list of cities and towns outside India that are publicly provided by the National Geospatial-Intelligence Agency. See the official website of the World Cities Database (https://simplemaps.com/data/world-cities) for more detailed explanations.
} 


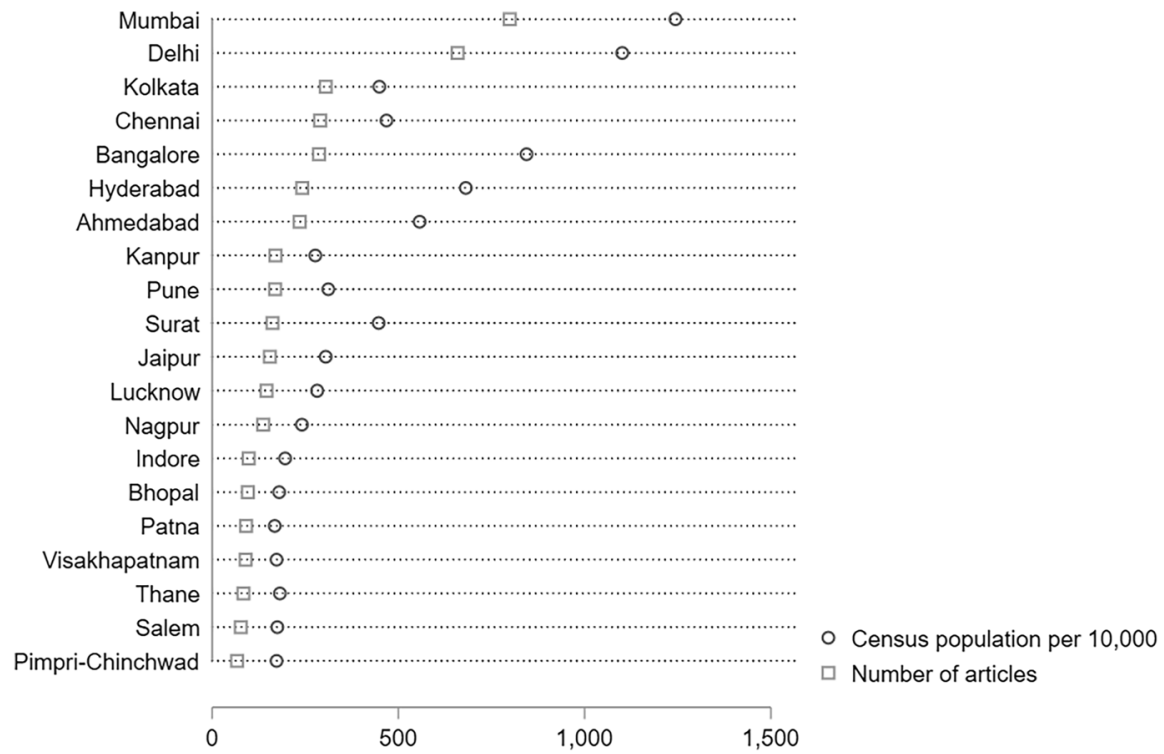

Fig. 2 Top 20 locations referenced in news articles: India. This figure presents top 20 locations referenced in news articles in India. A square-shaped dot denotes the number of unique articles speaking to the listed city, while a circle-shaped dot denotes total population per 10,000 in each city according to Census Survey 2011 in India. Note that since this figure is based on unique articles the number of articles does not count the same articles multiple times

The population of each location in the 2011 census is also plotted. The figure shows that the more populated a location is, the more often it is mentioned in corruptionrelated news. This is consistent with the fact that corruption is particularly prevalent in densely populated areas. In addition, the figure also shows that areas with smaller population sizes are also covered in corruption-related news a certain number of times. Thus, it is noted that corruption-related incidents appear in the news in many parts of India. In Panel A of Fig. 3, we plot the locations on a map. ${ }^{16}$ Here, we plot only the locations that appear more than 50 times to avoid complicating the figure, and we increase the size of the dots for locations that appear more than 150 times. From this figure, we can see that the areas covered in the corruption-related news are spread across India. In Panel B of Fig. 3, we plot the residential areas of the users. In this figure, if there are more than 10 users living in the same area, the size of the dot is increased. These figures indicate that the residential areas of the users are also spread across India, and they are exposed to news from various places.

Categorization of location-specific news articles. Next, we classify news articles containing geographic information into three categories: articles covering corruption cases involving politicians (politician's case); articles dealing with corruption cases involving officials and ordinary citizens (citizen's case); and other articles. For this task, we construct a complete list of the names of Indian politicians based on

\footnotetext{
16 This figure is based on our news database in which we do not count the same news articles multiple times, although the same articles can be circulated to between and within users in practice.
} 


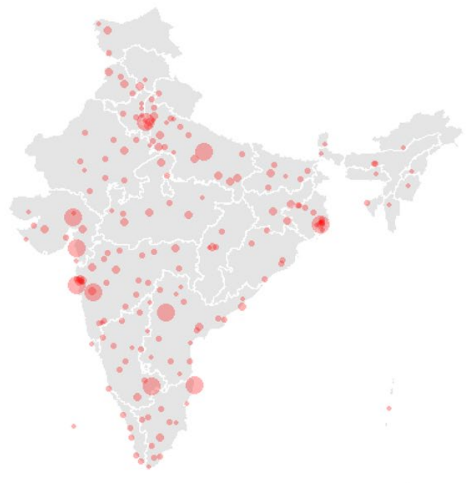

Panel A: Locations in News Articles

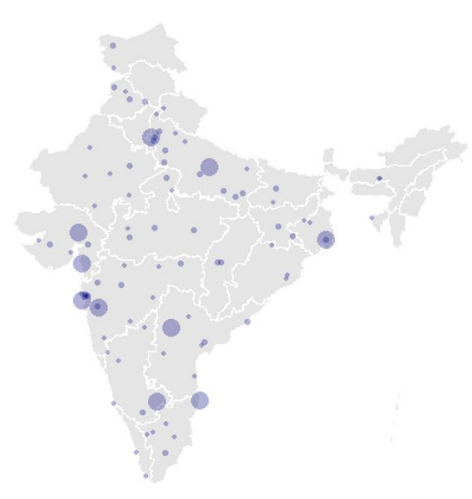

Panel B: Registered Users

Fig. 3 Maps of news locations and users. This figure depicts the maps of the locations referenced in news articles and registered users in our app. In Panel A, we plot the news locations. This panel is based on our news database in which we do not count same news articles multiple times although same articles can be circulated to between and within users in practice. We plot only the locations that appear more than 50 times to avoid complicating the figure, and we increase the size of the dots for locations that appear more than 150 times. In Panel B, we plot the residential areas of the users. In this panel, if there are more than 10 users living in the same area, the size of the dot is increased

the election results from 2010 to 2020 by developing algorithms scraping the official website of the Election of Commission of India. ${ }^{17}$ If a given article contains at least one politician's name and any keywords related to criminal cases, such as arrest, caught, book, accuse, or jail etc., it is classified as a politician's case. If a given article contains no politician's name but any keywords related to criminal cases, it is classified as a citizen's case. The rest of articles are classified as others. Of the total articles containing geographical information in India, $35.2 \%$ were assigned to the politician's case, $59.1 \%$ to the citizen's case, and the rest were classified as other articles. In terms of news outside India, it is difficult to construct a complete list of politicians' names. Therefore, we only use keywords related to political positions and criminal cases to identify the politician's and citizen's cases, respectively, following the same categorization rule with the domestic news. Of the total articles containing geographical information outside of India, $67.2 \%$ were assigned to the politician's case, $22.0 \%$ to the citizen's case, and the rest were classified as other articles.

Calculation of the distance to the news. Finally, we calculate the distance to the news based on the location-specific news articles that each user is exposed to during the experimental period. In the baseline survey, we asked all users to answer their residential location and thus, we can calculate the geographical distance between the

\footnotetext{
17 Since this method may not be able to collect complete information on the elections at the local body level, we complement the method by additionally treating an article as a politician case when it contains any keywords that refer to a political position, regardless of the fact that the name on the list does not exist in the article.
} 

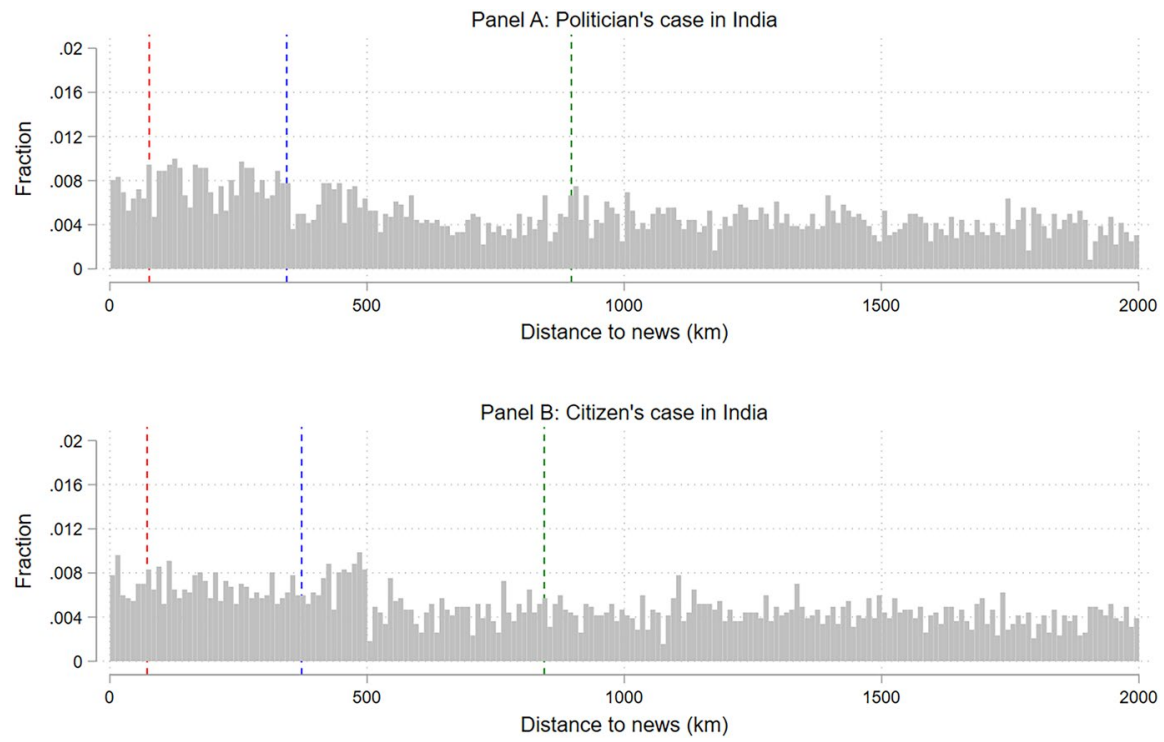

Fig. 4 Distribution of distance to locations referenced in news articles: India. Panel A of this figure shows the distribution of the distance to the locations referenced in news articles involving politicians, while Panel B shows the same distribution regarding news articles involving public officials and citizens. The distance is measured in a unit of $\mathrm{km}$. In this graph, we omit data if the distance exceeds $2000 \mathrm{~km}$ to make the graph easier to read. The red, blue, and green vertical lines are drawn at the bottom 5th, 25th, and 50th percentiles, respectively

location referenced in each news article and the users' residential places. We measure the distance separately for the news within and outside India. Panel C of Table 1 shows the summary statistics of the distance to the location referenced in the news articles. Note that the number of observations denotes the total number of news items that were actually distributed to the users during the experimental period and thus, this number would count the same news articles multiple times if they were distributed to multiple users at the same time. It would also be applied if they were distributed multiple times even within users during the experimental period. In terms of news articles in India, the average distance to the news location is equal to $946.66 \mathrm{~km}$ for the politician's case, while it is equal to $898.06 \mathrm{~km}$ for the citizen's case. Figure 4 shows the distribution of the distance to the news location in India. The red, blue, and green vertical lines denote the 5th, 25th, and 50th percentile points, respectively. The distance to the news is distributed over a range of 0 to $2000 \mathrm{~km}$, indicating it has considerable variations. This is consistent with the fact that news locations and users' residential areas are scattered across India, as shown above. 


\section{Empirical analysis}

In this section, we implement the main empirical analysis focusing on the impact of the distance to the news locations on the giving of bribery. First, we elaborate on our identification strategies. Second, we provide the main results which are followed by a number of robustness checks. Finally, we turn to examine the mechanisms behind the effect of the social media news on the bribe-giving behavior using additional information from the lab-in-the-app experiment.

\subsection{Identification strategies}

Our identification strategies rely on the exogenous variations between and within users in terms of the distance to the locations referenced in the news articles that are circulated to the users. First, we run the following regression models to estimate the impact of the distance to the news locations within and outside India, separately:

$$
\text { bribe }_{i, w}=\alpha+\delta \text { CitizenDist }_{i, w}+\eta \text { PoliticianDist }_{i, w}+\tau M_{i, w}+\pi X_{i, w-1}+\lambda_{d}+\theta_{i}+\varepsilon_{i, w},
$$

where bribe ${ }_{i, w}$ denotes the main outcome variable corresponding to the amount of bribe-giving by user $i$ to the anonymous public official in the lab-in-the-app experiment at week $w$. Note that, in our empirical analysis, the number of days included in week $w$ is not necessarily 7 days. Nevertheless, we stick to use the term "week", because it corresponds to the weekly experimental session. The reason why the number of days included between $w$ and $w+1$ is not necessarily 7 days comes from our flexible experimental design and a fixed redemption day (Thursday) of BWPs. That is, a user can play the experiment only once during 7 days from the redemption date from $d$ to $d+7$, where $d$ denotes a specific date of Thursday. However, the timing of when the user can play is not known in advance and is randomly determined by the pop-up. ${ }^{18}$ As a result, the longest week or $\bar{w}$ will include 14 days, and the shortest week or $w$ will be 0 days (less than $24 \mathrm{~h}$ ). For example, if a user plays the experiment right after the redemption at $d$, and then, plays it again 3 days after the next redemption at $d+7$, this user will have 10 days within week $w$ for this case. On the other hand, if a user plays the experiment immediately before the redemption at $d+7$ and then plays it again immediately after the redemption at $d+7$, only 1 day will be included in week $w$ for this case.

CitizenDist $_{i, w}$ and PoliticianDist ${ }_{i, w}$ denote the average distance to the locations referenced in news articles involving citizens and politicians, respectively. The average value is calculated based on all location-specific news delivered between $w$ and $w-1$, namely, between the day when bribe $_{i, w}$ is observed and the day when the experiment is played before that. We standardize these distance variables. $M_{i, w}$ and $X_{i, w-1}$ denote time-variant control variables for week $w$ and $w-1$, respectively. We control for the number of days included between $w$ and $w-1$ as $M_{i, w}$ and the amount

18 See also the explanation in Sect. 2.1 for more details. 
of bribes sent by other users who are matched with user $i$ in week $w-1$ as $X_{i, w-1} \cdot \lambda_{d}$ denotes the schedule fixed effects: the day-of-the-month fixed effects and the weekof-the-year fixed effects. We decide to include these fixed effects instead of the dayof-the-year fixed effects to avoid the decrease of the degree of freedom although the inclusion of the latter fixed effects is the most flexible specification. $\theta_{i}$ denotes the user fixed effects to control for time-invariant observable and unobservable attributes of each user.

To check the robustness of the estimation results using the average value, we also estimate the minimum and maximum values for the distance to the news distributed between $w$ and $w-1$. We also measure the impact of receiving the news with extremely close distances by creating a dummy that takes the value of one if the distance is below the 5th percentile of the overall distribution. The advantage of using such a dummy variable is that it allows us to test how closely people respond to the distance by gradually increasing the percentile cutoffs at which the dummy variable is created.

The parameters of interest are $\delta$ for the citizen's case and $\eta$ for the politician's case. On the one hand, if the coefficient is positive and statistically significant, it means that the exposure to the news of corruption cases occurring in close geographic distances decreases the amount of corruption. On the other hand, if the coefficient is negative and statistically significant, it means that the exposure to the news with a close geographic distance increases the amount of corruption.

\subsection{Main results}

Baseline results in India. Table 2 presents the estimation results of Eq. (1) for the domestic news. We use the average distance to the news locations as a key treatment variable from Columns (1) to (3); we use the minimum distance to the news locations from Columns (4) to (6); we use the maximum distance to the news locations from Columns (7) to (9). Time-variant control variables are included throughout specifications. Fixed effects are not included in Columns (1), (4), and (7); the user fixed effects are included in Columns (2), (5), and (8); the user fixed effects and the schedule fixed effects are included in Columns (3), (6), and (9). Notably, all the coefficients are statistically significant at the 10 percent level. In each specification, the impacts of the distance to the news locations on bribe-giving are consistently different between the news involving politicians and citizens. On the one hand, a decrease in the average distance to the news of a politician's involvement in corruption by one standard deviation increases the amount of the bribe-giving by 0.27 BWPs in the most conservative scale. Considering that the average amount of the giving of bribes is 11.19 BWPs, we can see that the magnitude of this coefficient is of a non-negligible scale. On the other hand, a decrease in the average distance to the news involving citizens and public officials by one standard deviation decreases the amount of the bribe giving by 0.26 BWPs. Again, this magnitude of the coefficient is on a scale that is economically important. These results are fairly robust to the inclusion of a variety of fixed effects. Looking at Columns (4) through (9), the results of the estimation using the average distance can be replicated by the estimations using the 


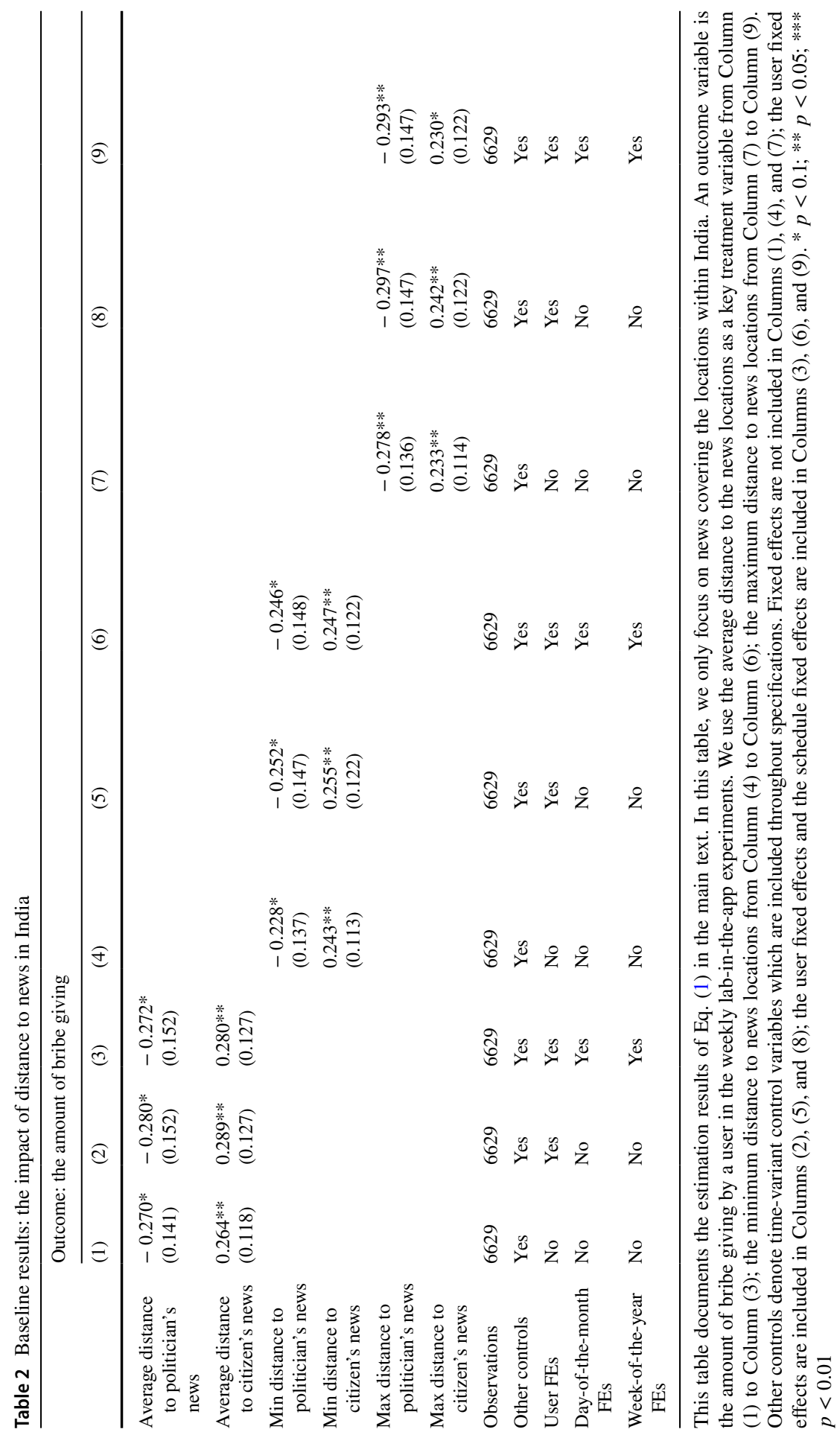


minimum and maximum values. The magnitudes of the estimated coefficients are very comparable, so we can conclude that these results are robust regardless of the method used to calculate the distance variables and the inclusion of the fixed effects in the estimation.

Baseline results outside India. Table 3 presents the estimation results of Eq. (1) for news outside India. Similar to Table 2, we separately estimate the equation using the average, minimum, and maximum distances to the news locations. According to this table, no coefficients are statistically significant and their absolute values are close to zero as compared to the estimation results for news within India. Therefore, these results suggest that people seem to consume news covering cases within India by paying much attention to the locations it refers to, while they pay little attention to the geographic information for the news covering cases outside India.

Responding to news close to one's own place? It would be interesting to examine whether people are particularly responsive to news that is close to them as compared to news that is distant from them. To investigate this, we decompose the distance-to-news variable into the dummy variables for each 5 th percentile and use them as treatment variables in Eq. (1). This allows us to determine which percentile of the distance variable is causing the overall effect. Panels A and B in Fig. 5 show the estimation results for the politician's and citizen's cases in India, respectively. From this figure, we obtain the following two facts. First, people react more strongly to news that is near their local areas. Second, people do not react to news that is distant from their local areas to a certain extent. Thus, the main result obtained above can be interpreted such that people increase the amount of bribery when exposed to corruption cases of politicians in close proximity and decrease it when exposed to corruption cases of ordinary citizens and public officials in close proximity. Here, the 5 th, 10th, and 15 th percentile points are equal to $74 \mathrm{~km}, 144 \mathrm{~km}$, and $211 \mathrm{~km}$ for the politician's case, respectively, while they are $71 \mathrm{~km}, 142 \mathrm{~km}$, and $208 \mathrm{~km}$ for the citizen's case. Therefore, these results are consistent with the speculation that people do not have a sense of reality for the news incidents that are too distant.

How long can users remember news? Do the results so far really prove that people change their bribe amount in response to the distance to the news locations? Using the facts that our app delivers a relatively large amount of news and that people's memory is limited, we can test the validity of the distance to the news effect. Specifically, the effect should diminish as the days go by, reflecting the fact that people's memories would fade. We decompose the effect of receiving the news whose distance is located in the bottom 5th percentile of the entire population by the number of days from the day the experiment was played. Figure 6 shows the estimation results for the news in India. In political corruption cases, people responded to the news delivered up to 3 days before playing the experiment at a statistically significant level. In the case of ordinary citizens, they respond to news delivered up to 2 days before. These results indicate that people make decisions about the bribe amounts based on their short-term memory of the locations mentioned in the news. 


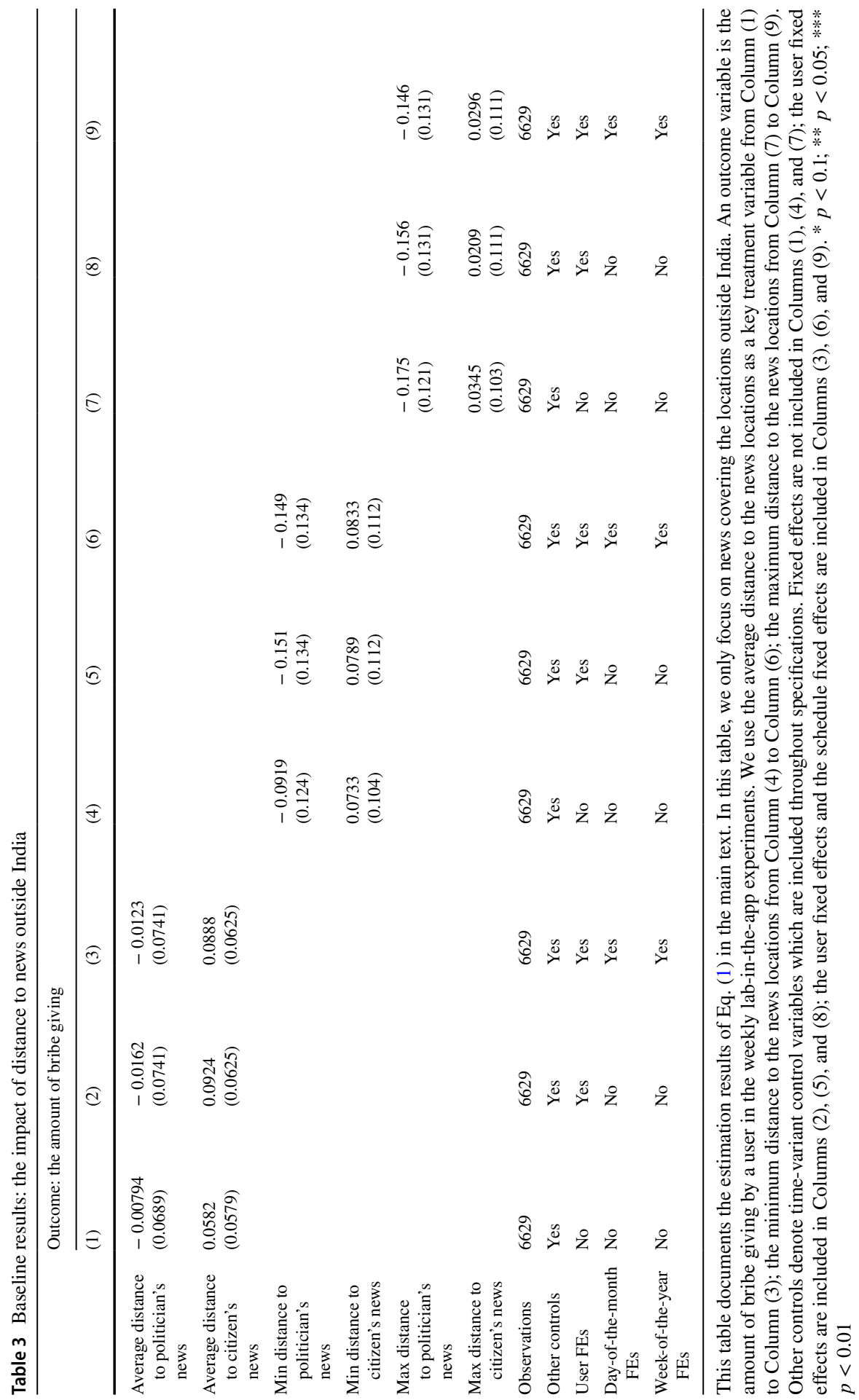



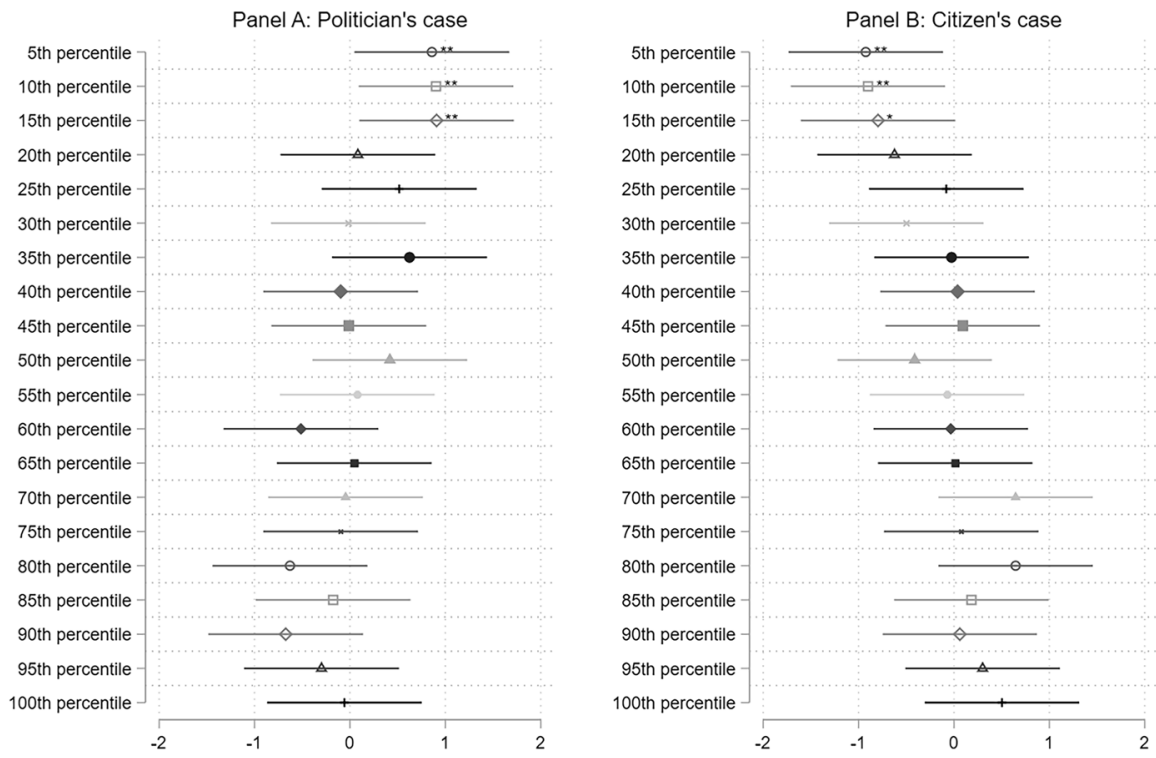

Fig. 5 Decomposition of the impacts of distance to news by percentiles. This figure plots the estimated coefficients for the decomposed impacts of the distance to the news by 5th percentiles. In this figure, we disaggregate the average distance variable in Eq. (1) into the dummy variables for each 5th percentile and use them as treatment variables in Eq. (1). Panels A and B of figure show the estimation results for the politician's case and the citizen's case in India, respectively. ${ }^{*} p<0.1 ; * * p<0.05 ; * * * p<0.01$

\subsection{Robustness checks}

Our results so far robustly show that exposure to geographically close news alters people's bribe amounts. Here, we further test the robustness of the results. If people are actually responding to geographically familiar news, then not only distance but also the boundaries of the community to which the news location belongs should matter. More specifically, the amount of the bribe should be affected if the news covers cases occurring in the same district or state with users' residential areas. To investigate the impact of the local news covering one's residential administration, we create two distinct variables on the number of times receiving news that speaks to their district and the number of times receiving news that speaks to their state. Then, we estimate the following model:

$$
\begin{aligned}
& \text { bribe }_{i, w}=\alpha+\beta \text { CitizenDistrict }_{i, w}+\sigma \text { PoliticianDistrict }_{i, w} \\
& +\tau M_{i, w}+\pi X_{i, w-1}+\lambda_{d}+\theta_{i}+\varepsilon_{i, w},
\end{aligned}
$$

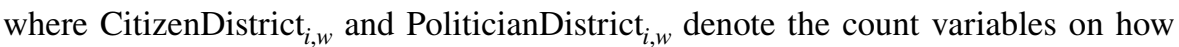
many local news covering citizen's cases and politician's cases in their own district is delivered to user $i$ in week $w$, respectively. Similarly, we estimate the same model for the impact of the local state's news by replacing CitizenDistrict ${ }_{i, w}$ and PoliticianDistrict $_{i, w}$ with CitizenState ${ }_{i, w}$ and PoliticianState ${ }_{i, w}$. These are the count 

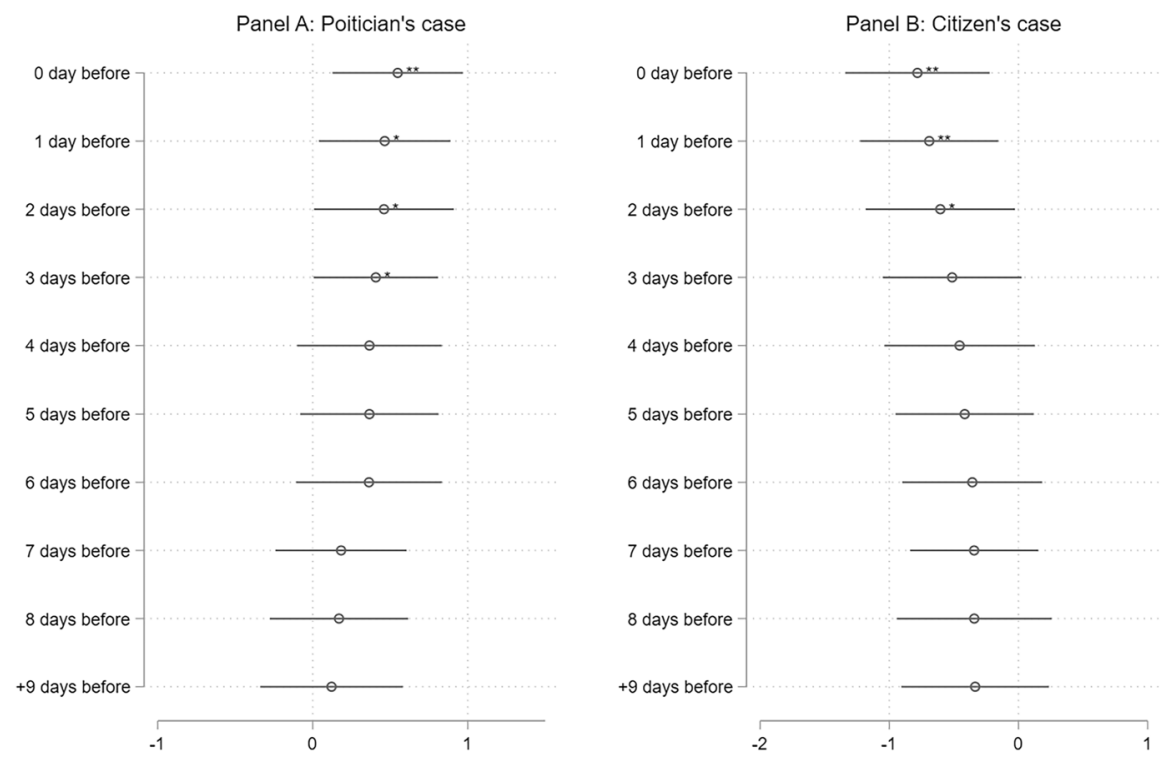

Fig. 6 Daily decomposition of the impacts of distance to news. This figure plots coefficients estimated based on Eq. (1). In this figure, we decompose the effect of receiving news whose distance is located in the bottom 5 th percentile of the entire population by the number of days, since the experiment was played. We only focus on the sub-sample including news inside India. " 0 day before" means that they receive news geographically close to them immediately before they play the experiment; " 5 days before" means that users receive news geographically close to them 5 days before playing the lab experiment. * $p<0.1 ; * * p<0.05 ; * * * p<0.01$

variables of how many local state news articles cover citizen's cases and politician's cases that are delivered to user $i$ in week $w$.

Table 4 presents the estimation results of Eq. (2). Column (1) through (3) show the impact of the exposure to the local news in their own district; Column (4) through (6) show the impact of the exposure to the local news in their own state. According to Column (1) through (3), as we predicted, the users will change the bribe amount in the lab when they are exposed to news about their district. If the news content is about corruption of politicians, the bribe amount will be increased; if the news content is about corruption of ordinary citizens and officials, the bribe amount will be decreased. To be more precise, receiving one more news article about a politician's corruption case will increase the bribe amount by 0.210 points in the most conservative scale. On the other hand, receiving one more news article of a corruption case of ordinary citizens and officials will increase the bribe amount by 0.208 points. These results are consistent with the above estimates using the average distance, and the magnitude of the coefficients is also compelling.

Interestingly, when we look at the impacts of the local state news shown in Columns (4)-(6), the coefficients are statistically significant for the politician's case, while they are not statistically significant for the citizen's case. These results imply the following two stories. First, a corruption case involving a state legislator or local legislator from another district within a state has a significant impact on users. 


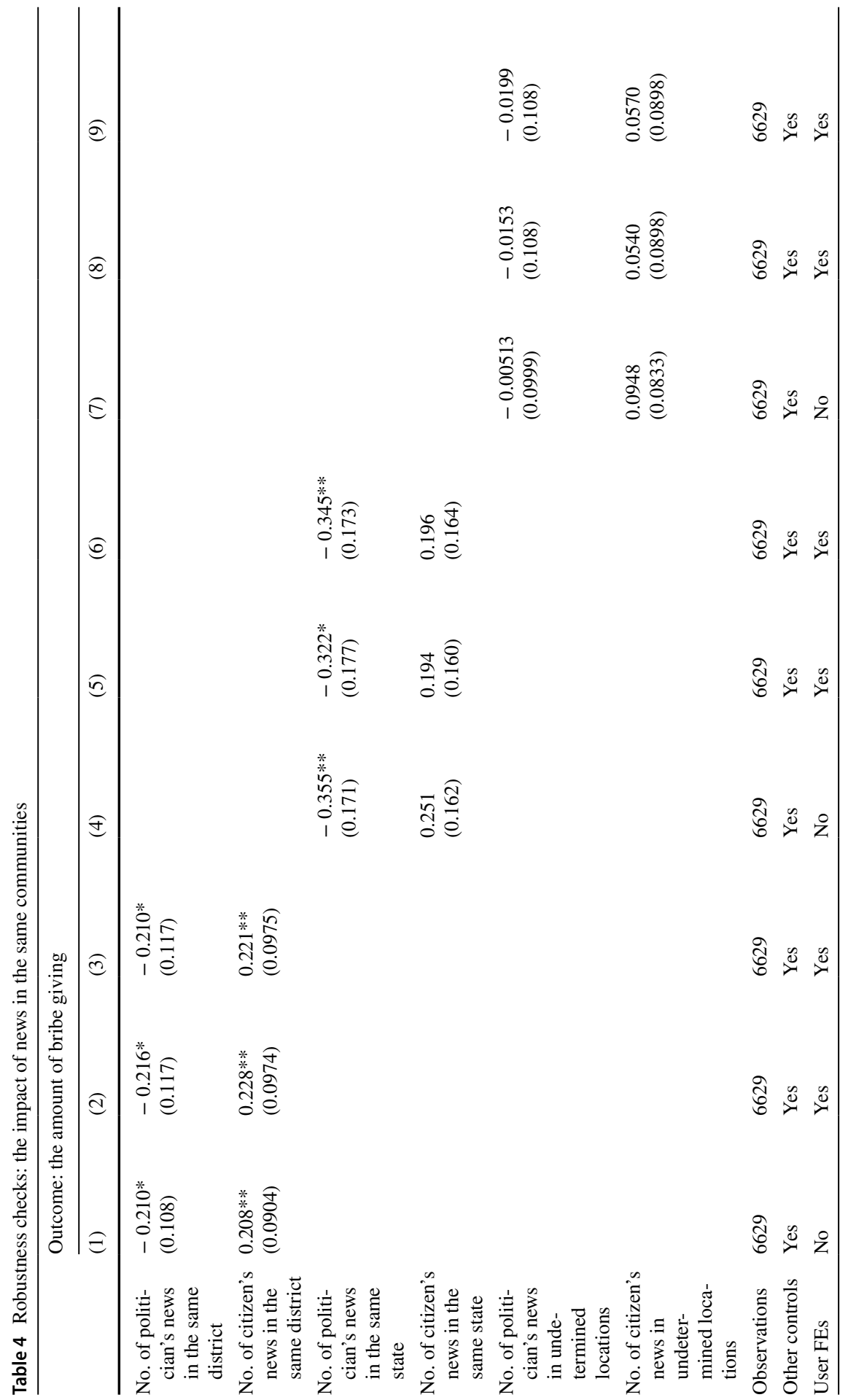




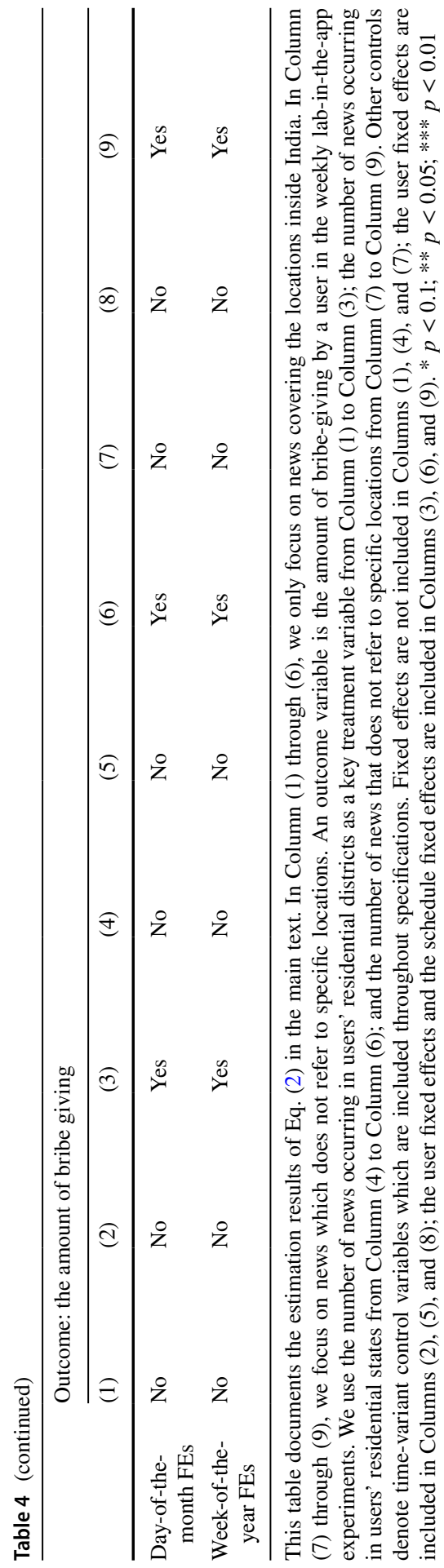


Presumably, knowing that a politician who represents one's own region is involved in corruption decreases the moral cost related to this illegal action and increases the amount of bribes in the lab. Second, when exposed to corruption cases between ordinary citizens and officials, users are likely to perceive the cases as familiar if they occur in the same district, but not so familiar if they occur in the same state. This is plausible when we consider the geography of India, where even within the same state there are often hundreds of kilometers or more of separation.

Finally, we perform a placebo test using the number of times the users are exposed to the news that does not contain geographical information and locations. According to Columns (7)-(9), as predicted, all the estimated coefficients are not statistically significant, and the absolute values of the coefficients are relatively close to zero. Therefore, it appears certain that users change their bribe amounts in response to the locations covered in the news.

\subsection{Mechanisms}

The results so far show that people increase the amount of bribes when they are exposed to corruption cases of politicians in a close geographic proximity, and decrease the amount of bribes when they are exposed to the corruption cases of ordinary citizens and officials in a close geographic proximity. The question then arises: What is the mechanism behind them? In this subsection, we examine the role of the moral costs in explaining these results using additional information coming from the lab-in-the-app experiment.

We hypothesize that the corruption news occurring within close geographic areas influences the moral costs and subsequently these moral costs affect the amount of giving bribes. More specifically, on the one hand, when people learn that a politician, who should be a representative role model for the general public, is engaging in corruption, the moral costs of corruption decrease and consequently the amount of bribes increases. On the other hand, when they learn that an ordinary citizen who is in the same position as themselves has been arrested for engaging in corruption, they may reaffirm that corruption is an antisocial act, which increases the moral costs of paying bribes and reduces the amount of bribes in the lab experiment. It is important to note that our design eliminates the effect of subjective probability of being arrested, because the possibility that users are actually arrested due to decisions inside the lab is fully ruled out by design.

To test these hypotheses, we will use information on the amount of bribes sent by other users as the citizen in a previous session of the lab experiment. ${ }^{19}$ Since the moral cost itself is unobservable, we indirectly test the degree of the moral cost by examining whether users conform to the bribe amounts of other users. If each user's moral cost is relatively low, we expect that they are more likely to conform to other users who give a large amount of bribes. However, if the moral cost is relatively

\footnotetext{
19 Remember that our experimental design allows users to observe other user's bribe amount if they are assigned to the roles except for the citizen.
} 
high, they will not easily conform to other users who are engaging in bribery. In other words, we assume that the degree of moral costs is negatively associated with the tendency of conforming to other user's bribe amount.

Based on this assumption, we estimate the following equation:

$$
\begin{aligned}
& \text { bribe }_{i, w}=\phi+\gamma \text { OtherBribe }_{i, w-1}+\kappa \text { CitizenDistDummy }_{i, w}+\mu \text { PolDistDummy }_{i, w} \\
& +\rho \text { CitizenDistDummy }_{i, w} \times \text { OtherBribe }_{i, w-1} \\
& +\zeta \text { PolDistDummy }_{i, w} \times \text { OtherBribe }_{i, w-1} \\
& +\tau M_{i, w}+\lambda_{d}+\theta_{i}+\varepsilon_{i, w}
\end{aligned}
$$

where OtherBribe ${ }_{i, w-1}$ denotes the amount of bribe giving by other users as the cit-

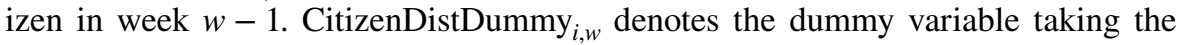
value of one if a user receives the local news covering a citizen's case that is geographically close enough to be placed in the 5th percentile of the entire distribution.

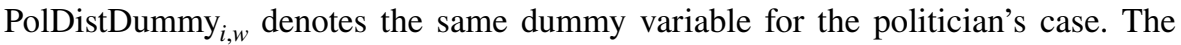
parameters of interest are $\gamma, \rho$, and $\zeta$. Note that $\gamma$ captures the tendency of conformity to other user's bribe amount. Through the sign and magnitude of $\rho$ and $\zeta$, we can test how receiving news at close distance changes the tendency of conforming to other's bribe amounts.

Table 5 presents the estimation results of Eq. (3). Panel A corresponds to the result using the 5th percentile dummy variable. The coefficient of the interaction term between the politician's news dummy and the other user's bribe amount is positive although it is not statistically significant. Combined with the fact that the coefficient for the other user's bribe amount is positive and statistically significant, it indicates that if users receive news about a corruption case involving a politician within their geographic proximity, they are more willing to conform to the bribing behavior by others and increase their bribe amount. This is compatible with the hypothesis that such politician's news will decrease moral costs committing a bribe. In terms of the coefficient of the interaction term between the citizen's news dummy and the other user's bribe amount, it is negative and statistically significant. Since the absolute value of the coefficient is almost same with the one for the other user's bribe amount, it implies that when receiving news about corruption cases of ordinary citizens within a close geographical area, they quit conforming to the bribing behavior of others.

In Panels B and C, we alternatively use the local news dummy variables taking the value of one if a user receives the local news that is geographically close enough to be placed in the 25th and 50th percentiles of the entire distribution. As predicted, the effect on the moral costs diminishes as the distance to the news increases. At the 50th percentile, the effect disappears completely. We further perform a placebo test by exploiting our experimental design in which a user cannot observe other user's bribe amount if their role is the citizen. Thus, since a user cannot know the bribery behavior by other users, the conformity to other user's bribery behavior should disappear when we focus on this specific situation. Table 6 presents the results of this placebo test. Here, all the coefficients for the interaction terms between the citizen's news dummy and the other user's bribery amounts become statistically insignificant. 


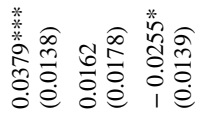

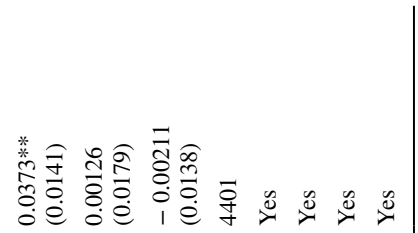

홀

롤 윰

要起

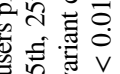
ป

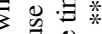

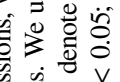

究 $\frac{1}{0}=$

펼 当

远

这

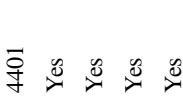

요 월 $\overrightarrow{\mathrm{D}}^{*}$

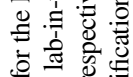

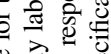

永记

可.

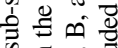

क $\cong$ ष

范要

क न

ठิ

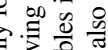

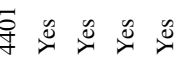

ธิ

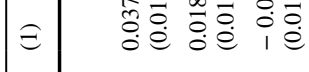

\&

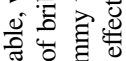

声完

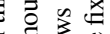

$\Xi$ ㅋㅀㅇㅠ

这导 㐘 


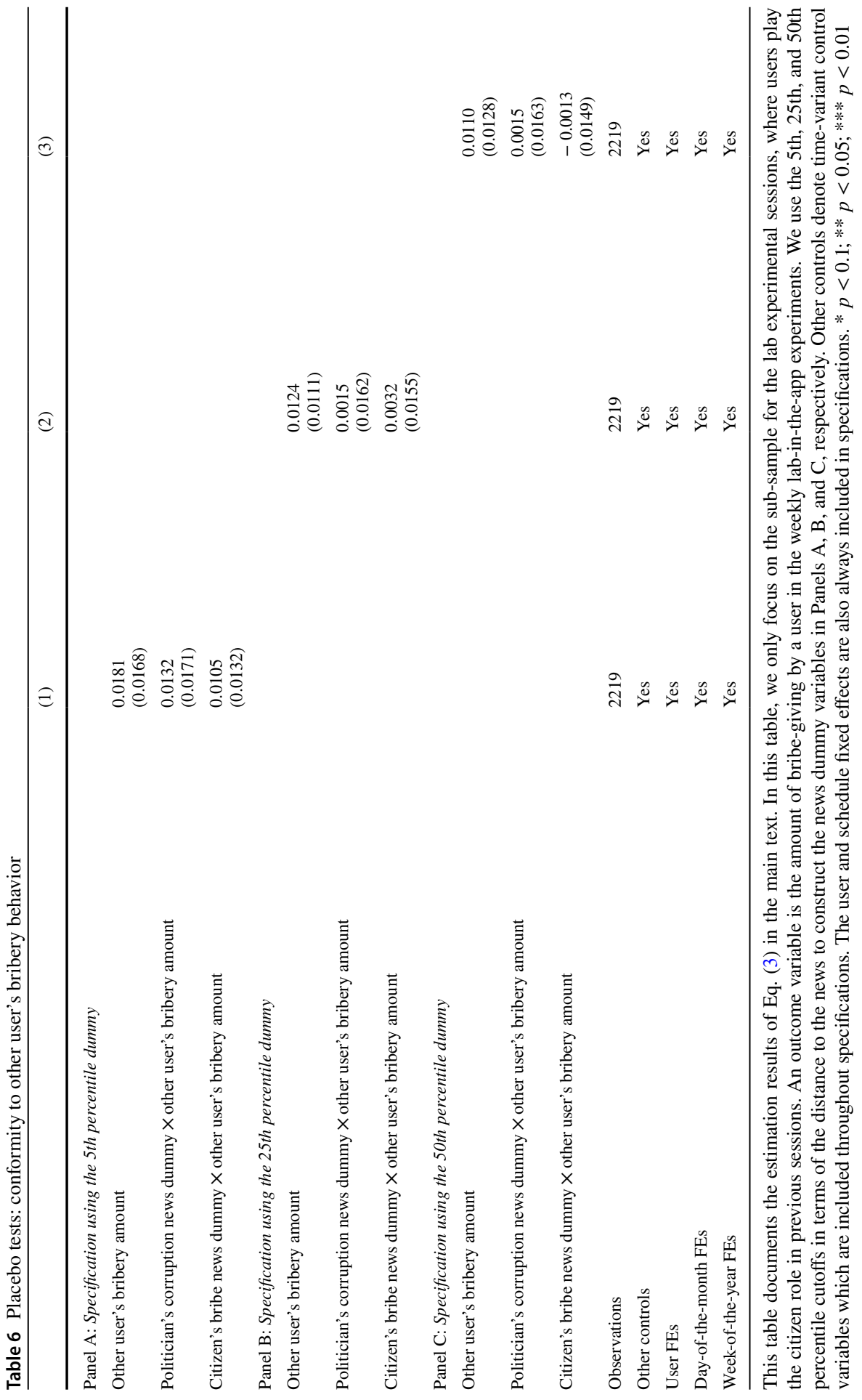


This implies that the users actually observe other user's bribing behavior and conform to it.

In sum, these estimation results consistently show that corruption cases involving politicians within a close geographical proximity increase bribe amounts by decreasing the moral costs against the bribery behavior, while corruption cases involving ordinary citizens and officials increase the moral costs and result in a decrease in the bribe amounts.

\section{Conclusion}

This paper investigates how the exposure to the news about corruption within a geographic proximity affects the bribe-giving behavior of ordinary citizens. Combining the field and lab experiments using the original app, we are able to obtain the following findings. First, we find that when politicians are involved in corruption cases, knowing that someone who should be a representative role model is involved in corruption and decreasing the moral costs against bribery, the users attempt to increase the amount of bribery. Second, when the corruption involved ordinary citizens and public officials who are in the same position as themselves, the users reaffirm that bribery is an anti-social behavior and their moral costs increase, leading them to refrain from giving bribery.

The evidence we provide in this study has important policy implications. First, it is important to note that the role of the local news that is geographically close to the user is very significant. However, it is a double-edged sword. Making the public aware of the fact that ordinary citizens in the same position as themselves are subject to the penalties for corruption can have a positive effect on reducing corruption. On the other hand, the corrupt behavior of exemplary individuals such as politicians may decrease the moral costs and increase bribery. Second, it suggests that attempts to prevent corruption among the politicians discussed in the literature are also an effective policy for reducing bribing behavior by citizens, because it circumvents a decrease in the moral cost of the general public by lowering the frequency of being exposed to politician's corruption news in local areas.

Acknowledgements We thank Lata Gangadharan, Masao Ogaki, and participants at the International Workshop for Lab and Field Experiments (co-organized by Japanese Economic Association; Research Center for Behavioral Economics, Institute of Social and Economic Research at Osaka University; and Research Institute for Socionetwork Strategies at Kansai University). This research was financially supported by the Japan Society for the Promotion of Science [Grant-in-Aid for Scientific Research (B): 19H01489]. Approval from IRB at Hitotsubashi University (2019C014).

Open Access This article is licensed under a Creative Commons Attribution 4.0 International License, which permits use, sharing, adaptation, distribution and reproduction in any medium or format, as long as you give appropriate credit to the original author(s) and the source, provide a link to the Creative Commons licence, and indicate if changes were made. The images or other third party material in this article are included in the article's Creative Commons licence, unless indicated otherwise in a credit line to the material. If material is not included in the article's Creative Commons licence and your intended use is not permitted by statutory regulation or exceeds the permitted use, you will need to obtain permission directly from the copyright holder. To view a copy of this licence, visit http://creativecommons.org/licen ses/by/4.0/. 


\section{References}

Abbink, K. (2006). Laboratory experiments on corruption. In International Handbook on the Economics of Corruption (pp. 418-437). Edward Elgar Publishing

Abbink, K., Freidin, E., Gangadharan, L., \& Moro, R. (2018). The effect of social norms on bribe offers. The Journal of Law, Economics, and Organization, 34(3), 457-474.

Alatas, V., Cameron, L., Chaudhuri, A., Erkal, N., \& Gangadharan, L. (2009). Subject pool effects in a corruption experiment: A comparison of Indonesian public servants and Indonesian students. Experimental Economics, 12(1), 113-132.

Banuri, S., \& Eckel, C. (2012a). The effects of sanctions on bribery: US versus Pakistan. In Technical report. CBEES Working Paper Series 09-01.

Banuri, S., \& Eckel, C. (2012b). Experiments in culture and corruption: A review. Policy Research Working Paper; No. 6064. World Bank, Washington, DC.

Barr, A., \& Serra, D. (2010). Corruption and culture: An experimental analysis. Journal of Public economics, 94(11-12), 862-869.

Bertrand, M., Djankov, S., Hanna, R., \& Mullainathan, S. (2007). Obtaining a driver's license in India: An experimental approach to studying corruption. The Quarterly Journal of Economics, 122(4), 1639-1676.

Bicchieri, C., Dimant, E., Gächter, S., \& Daniele, N. (2020). Observability, social proximity, and the erosion of norm compliance. CESifo Working Paper.

Boxell, L., Gentzkow, M., \& Shapiro, J. M. (2017). Greater internet use is not associated with faster growth in political polarization among us demographic groups. Proceedings of the National Academy of Sciences, 114(40), 10612-10617.

Bursztyn, L., Fiorin, S., Gottlieb, D., \& Kanz, M. (2019). Moral incentives in credit card debt repayment: Evidence from a field experiment. Journal of Political Economy, 127(4), 1641-1683.

Bursztyn, L., \& Jensen, R. (2017). Social image and economic behavior in the field: Identifying, understanding, and shaping social pressure. Annual Review of Economics, 9, 131-153.

Cameron, L., Chaudhuri, A., Erkal, N., \& Gangadharan, L. (2009). Propensities to engage in and punish corrupt behavior: Experimental evidence from Australia, India, Indonesia and Singapore. Journal of Public Economics, 93(7-8), 843-851.

Dimant, E. (2019). Contagion of pro-and anti-social behavior among peers and the role of social proximity. Journal of Economic Psychology, 73, 66-88.

Gazzaniga, M. S. (2005). The ethical brain. Dana Press.

Knack, S., \& Keefer, P. (1995). Institutions and economic performance: Cross-country tests using alternative institutional measures. Economics \& Politics, 7(3), 207-227.

Levitt, S. D., \& List, J. A. (2007). What do laboratory experiments measuring social preferences reveal about the real world? Journal of Economic Perspectives, 21(2), 153-174.

Levy, R. (2021). Social media, news consumption, and polarization: Evidence from a field experiment. American Economic Review, 111(3), 831-870.

Mauro, P. (1995). Corruption and growth. The Quarterly Journal of Economics, 110(3), 681-712.

Olken, B. A., \& Pande, R. (2012). Corruption in developing countries. Annual Review of Economics, 4(1), 479-509.

Prior, M. (2013). Media and political polarization. Annual Review of Political Science, 16, 101-127.

Publisher's Note Springer Nature remains neutral with regard to jurisdictional claims in published maps and institutional affiliations. 